\title{
FXR: a metabolic regulator and cell protector
}

\author{
Yan-Dong Wang ${ }^{1}$, Wei-Dong Chen ${ }^{1}$, David D Moore ${ }^{2}$, Wendong Huang ${ }^{1}$ \\ ${ }^{1}$ Department of Gene Regulation and Drug Discovery, Beckman Research Institute, City of Hope National Medical Center, 1500 E. \\ Duarte Road, Duarte, CA 91010, USA; ${ }^{2}$ Department of Molecular and Cellular Biology, Baylor College of Medicine, One Baylor \\ Plaza, Houston, TX 77030, USA
}

Farnesoid $\mathrm{X}$ receptor (FXR) is a member of the nuclear receptor superfamily of ligand-activated transcription factors. As a metabolic regulator, FXR plays key roles in bile acid, cholesterol, lipid, and glucose metabolism. Therefore, FXR is a potential drug target for a number of metabolic disorders, especially those related to the metabolic syndrome. More recently, our group and others have extended the functions of FXR to more than metabolic regulation, which include anti-bacterial growth in intestine, liver regeneration, and hepatocarcinogenesis. These new findings suggest that FXR has much broader roles than previously thought, and also highlight FXR as a drug target for multiple diseases. This review summarizes the basic information of FXR but focuses on its new functions.

Keywords: FXR, bile acid, metabolism, liver regeneration, hepatocarcinogenesis

Cell Research (2008) 18:1087-1095. doi: 10.1038/cr.2008.289; published online 30 September 2008

\section{Introduction}

Nuclear receptors (NRs) are ligand-activated transcription factors that have central roles in nearly every aspect of development and adult physiology [1]. This family contains 48 members in humans. Because of the importance of NR functions in different metabolic pathways, they have become attractive targets for drug discovery.

Initially cloned and named as the farnesoid X receptor (FXR, NR1H4) in 1995 [2], FXR belongs to a subcluster of metabolic receptors that also include vitamin D receptor (VDR, NR1I1), constitutive androstane receptor

\footnotetext{
Correspondence: Wendong Huang

Tel: +1-626-256-4673 Ext 65203

E-mail: whuang@coh.org

Abbreviations: BACS (bile acid CoA synthetase); BAT (bile acidCoA:amino acid $\mathrm{N}$-acetyltransferase); BSEP (bile salt export pump); IBABP (intestinal bile acid binding protein); MRP2 (multidrug resistantassociated protein 2); OATP8 (organic anion transporting polypeptide 8); hOST $\alpha /$ hOST $\beta$ (human organic solute transporters $\alpha / \beta$ ); SHP (small heterodimer partner); STD (dehydroepiandrosterone sulfotransferase); ASBT (apical sodium-dependent bile acid cotransporter); CYP7A1 (cholesterol $7 \alpha$-hydroxylase); CYP8B1 (cytochrome P450 sterol 12 $\alpha$-hydroxylase); MDR3 (multidrug resistance protein 3); PLTP (phospholipid transfer protein); SDC1 (Syndecan-1); VLDLR (the very low density lipoprotein receptor); ApoA-I (apolipoprotein A-I); Apo CIII (apolipoprotein CIII); PEPCK (Phosphoenolpyruvate carboxykinase); G6Pase (glucose-6-phosphatas)
}

(CAR, NR1I3), pregnane $X$ receptor (PXR, NR1I2), and liver $X$ receptor alpha and beta $(\mathrm{LXR} \alpha, \mathrm{NR} 1 \mathrm{H} 3$; LXR $\beta$, $\mathrm{NR} 1 \mathrm{H} 2$ ). As a transcription factor, it binds to DNA either as a monomer or as a heterodimer with a common partner for NRs, retinoid X receptor (RXR, NR2B1), to regulate the expression of various genes involved in bile acid (BA), lipid, and glucose metabolisms [3]. FXR is highly expressed in the liver, intestine, kidney, and adrenals, but with lower expression in fat and heart $[2,4$, 5]. FXR protein has the typical NR structure composed of modular domains, the N-terminal ligand-independent transcriptional activation AF1 domain (AB), the DNAbinding $\mathrm{C}$-domain, a $\mathrm{D}$ domain and hinge region, and the $\mathrm{C}$-terminal ligand-binding $\mathrm{E}$ domain containing the ligand-dependent AF2 activation domain [6-8]. There are two FXR genes (FXR $\alpha$ (NR1H4) and FXR $\beta$ (NR1H5)) in mammals [9]. FXR $\beta$ is a functional receptor in mice, rats, rabbits, and dogs, but constitutes a pseudogene in humans and primates [10]. The functional role of FXR $\beta$ is not clear yet. A single FXR $\alpha$ gene encodes FXR $\alpha 1$ or $\alpha 2$ and FXR $\alpha 3$ or $\alpha 4$ isoforms resulting from the differential use of two promoters and an alternative splicing by using two different sites in exon $5[5,11,12]$. The four isoforms are expressed in a tissue-dependent manner [5]. FXR $\alpha$ is most abundantly expressed in the liver. FXR $\alpha 1$ and FXR $\alpha 2$ are moderately expressed in ileum and adrenal gland. FXR $\alpha 3$ and FXR $\alpha 4$ are abundantly expressed in ileum, moderately in kidney, and at low levels in 
stomach, duodenum, and jejunum [5]. By regulating the expression of genes involved in diverse metabolic pathways, FXR is becoming an attractive drug target for different metabolic diseases. More recently, we showed that
FXR regulates liver regeneration, thereby linking BA signaling to liver re-growth [13]. In addition, FXR null mice spontaneously developed liver tumors as they aged $[14,15]$. These new findings suggest that FXR has much

Table 1 Summary of related FXR information

\begin{tabular}{|c|c|}
\hline Gene & $\begin{array}{l}\text { NR1H4 } \\
12 q 23.3\end{array}$ \\
\hline Expression & $\begin{array}{l}\text { Liver } \\
\text { Small intestine } \\
\text { Kidney } \\
\text { Adrenals } \\
\text { Vascular smooth muscle } \\
\text { Adipose tissue } \\
\text { Breast cancer }\end{array}$ \\
\hline Natural agonists & $\begin{array}{l}\text { Primary bile acid: CA, CDCA } \\
\text { Secondary bile acid: LCA, DCA } \\
\text { Polyunsaturated fatty acids: arachidonic acid; docosahexaenoic acid, and linolenic acid } \\
\text { (endogenous and selective bile acid receptor modulators that specifically regulate expression of } \\
\text { certain FXR targets) [21] } \\
\text { Bile acid metabolites: 26- or 25-hydroxylated bile alcohols [22] } \\
\text { Oxysterols: oxysterol 22(R)-hydroxysholesterol [19] } \\
\text { Androsterone (very weak activity) [20] } \\
\text { The order of potency of these ligands: } 26 \text { - or 25-hydroxylated bile alcohols=CDCA }>\text { LCA=DCA }>C A\end{array}$ \\
\hline Synthetic agonists & $\begin{array}{l}\text { GW4064 (high-affinity agonist), 6ECDCA (semisynthetic bile acid), AGN29 [23], AGN31 [23] } \\
\text { The potency of these ligands: } \\
\text { GW4064 and 6ECDCA are more potent than the bile acids } \\
\text { AGN29 and AGN31 are FXR-selective ligands and 25-fold more potent than naturally occurring ligands }\end{array}$ \\
\hline Antagonists & Guggulsterone, lithocholate, AGN34 [23] \\
\hline Response elements & $\begin{array}{l}\text { IR-1: GAGTTAaTGACCT } \\
\text { GGGTGAaTAACCT } \\
\text { GGGACAtTGATCCT } \\
\text { AGGTCAaGTGCCT } \\
\text { GGGTCAgTGACCC } \\
\text { DR-1: AGAGCAnAGGGGA } \\
\text { ER-8: TGAACTcttaaccaAGTTCA } \\
\text { Monomer binding site: GATCCTTGAACTCT } \\
\text { TGAACT }\end{array}$ \\
\hline Relevant diseases & $\begin{array}{l}\text { Cholestasis } \\
\text { Diabetes } \\
\text { Atherosclerosis } \\
\text { Cholesterol gallstone disease } \\
\text { Liver regeneration } \\
\text { Liver inflammation } \\
\text { Hepatocarcinogenesis } \\
\text { Breast cancer } \\
\text { Colon cancer }\end{array}$ \\
\hline
\end{tabular}


broader roles than previously thought.

In this review, we summarize the basic properties of FXR including its ligands and target genes, but focus on its new functions. Specifically, we will discuss the impact of these new findings on the studies of liver regeneration and hepatocarcinogenesis.

\section{The ligands of FXR}

Ligand identification for NRs always greatly facilitates their research. FXR was originally proposed to be a receptor for an intermediary metabolite, farnesol [2]. However, the supraphysiological concentrations required to activate FXR impede the use of farnesoid as a ligand. The major breakthrough in FXR biology was the discovery that BAs are endogenous ligands for this NR [16-18]. In fact, both conjugated and unconjugated bile salts are able to activate FXR at physiological concentrations. The hydrophobic BA chenodeoxycholic acid (CDCA) is the most effective activator of FXR. Deoxycholic acid (DCA) and lithocholic acid (LCA) can both activate FXR, but to a much lesser extent than CDCA, whereas hydrophilic ursodeoxycholic (UDCA) and muricholic acids cannot activate FXR [17]. Recently, Deng et al. [19] and Wang et al. [20] reported that oxysterol 22(R)-hydroxycholesterol and androsterone are natural FXR ligands, respectively (Table 1). However, whether they represent bona fide endogenous ligands of FXR and the physiological consequences of FXR activation by them remain to be established (Table 1). Some polyunsaturated fatty acids such as arachidonic acid and decosahexaenoic acid [21] and BA metabolites such as 26- or 25-hydroxylated bile alcohols [22] were also identified as weak FXR ligands. In addition, several synthetic FXR ligands have been generated. They include GW4064, 6ECDCA, AGN29 [23], and AGN31 [23]. The most widely used FXR ligand is the non-steroidal isoxazole analog GW4064 [24]. But the potential cell-toxic effect and uncertain bioavailability restrict its further use. Instead, $6 \alpha$-ethylchenodeoxycholic acid (6-ECDCA), a novel compound derived from the natural FXR ligand CDCA, has become an alternative agonist ligand for FXR [25-27].

\section{FXR and its target genes}

The function of FXR has been shown to be related to different diseases including cholestasis, diabetes, atherosclerosis, and cholesterol gallstone disease. A number of excellent reviews on roles of FXR in these diseases have been published recently [12, 28-31]. FXR fulfills its regulatory role by controlling the expression of a variety of genes in cognate metabolic pathways. Here we briefly summarize the identified FXR-binding elements and its target genes.

FXR regulates the expression of a wide variety of target genes by binding either as a monomer or as a heterodimer with RXR to FXR response elements (FXREs). Typical FXREs consist of an inverted repeat (IR) of the

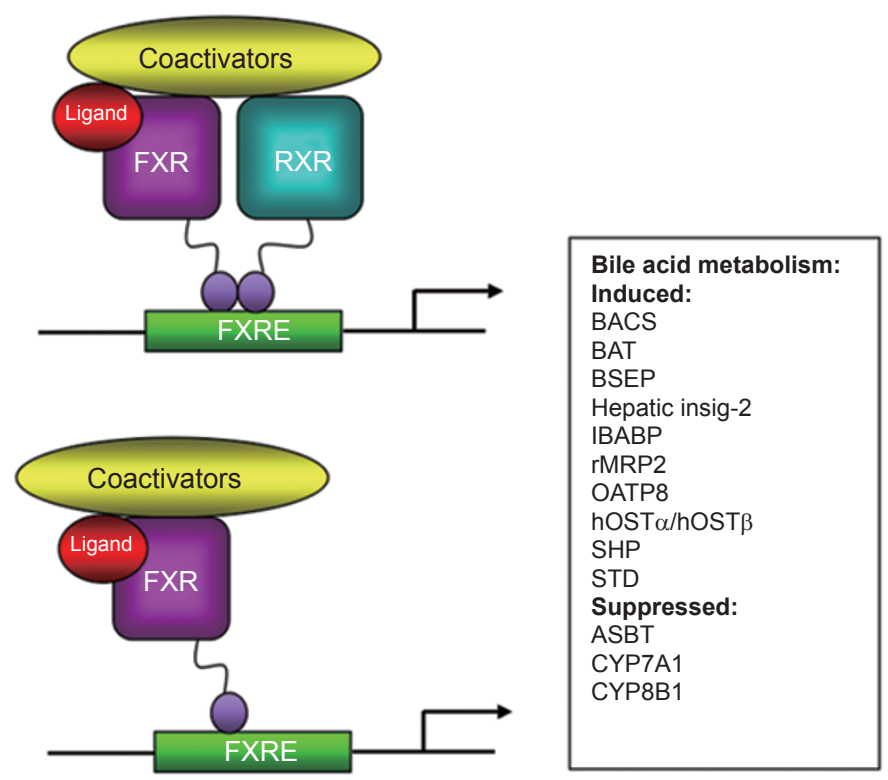

\begin{tabular}{l}
\hline Lipoprotein metabolism: \\
Induced: \\
Apolipoprotein C-II \\
Apolipoprotein E \\
Human complement C3 \\
MDR3 \\
PLTP \\
SDC1 \\
VLDLR \\
Suppressed: \\
ApoA-1 \\
Hepatic lipase \\
Apo CIII \\
\hline Glucose metabolism: \\
PEPCK \\
G6Pase \\
\hline
\end{tabular}

Figure 1 FXR regulates a large number of target genes involved in bile acid, lipoprotein and glucose metabolisms. FXR binds to DNA either as a heterodimer with RXR or as a monomer to regulate the expression of various genes. 
canonical AGGTCA hexanucleotide core motif spaced by 0 bp (IR-0) [32] or 1 bp (IR-1) [33, 34]. IR-1 is the primary binding sequence for FXR. FXR regulates human intestinal bile acid binding protein (IBABP), small heterodimer partner (SHP), bile salt export pump (BSEP), BA-CoA:amino acid $N$-acetyltransferase (BAT) [35] and phospholipid transfer protein (PLTP) via IR-1 elements in the promoters of these genes [36-39]. Besides IR-1, other FXREs include IR-0, direct repeat (DR), everted repeat [13] of the core motif separated by eight nucleotides (ER-8) and monomeric binding sites [32, 4043] (Table 1). In summary, FXR can bind to a variety of FXREs with varied affinities.

By binding to FXREs, FXR regulates many genes belonging to different metabolic pathways (Figure 1). Activation of FXR alters the expression of different groups of genes involved in BA homoeostasis, lipid metabolism, and glucose balance. FXR is the primary sensor of BAs. FXR activates the expression of short heterodimer partner (SHP), which in turn binds to and inactivates liver receptor homolog 1 (LRH-1, NR5A2), thus potently inhibiting the expression of cholesterol $7 \alpha$-hydroxylase (CYP7A1), the rate-limiting enzyme in BA biosynthesis $[37,44]$. In addition, it is clear that BA activation of FXR in the intestine leads to the induction of mouse Fgf15 [45] or its human ortholog FGF19 [46], thereby suppressing CYP7A1 expression through a JNK-dependent signaling cascade. BAs are end products of cholesterol catabolism. As such, FXR also activates the expression of hepatic Insig-2, which represses cholesterol synthesis [47]. These findings indicate that FXR not only directly suppresses the synthesis of BAs, but also inhibits the synthesis of cholesterol, the precursor for BAs. A constant pool of BAs was maintained by enterohepatic circulation. In addition to regulating BA synthesis, FXR controls the recycling of BAs by regulating genes involved in BA secretion, transportation, absorption, conjugation, and detoxification [34, 42]. The remarkable ability of FXR to regulate BA metabolism is confirmed by loss-of-function studies on FXR in animal model [15, 48, 49]. Therefore, FXR is also called the BA receptor due to its master effect on BA homeostasis.

Analyses of FXR knockout animals also reveal an unexpected role of FXR in lipid metabolism. It was shown that FXR also regulates a set of genes that participate in lipoprotein metabolism. These include genes for PLTP, SDC-1, the very low density lipoprotein receptor (VLDLR), apolipoprotein C-II, and apolipoprotein E [50-52]. All these genes are involved in the metabolism of plasma lipoproteins. In addition, activation of FXR leads to repression of SREBP-1c, a transcription factor that controls genes involved in fatty acid and triglyceride synthesis [53,
54]. Therefore, FXR plays an important role in regulating lipid metabolism.

Because of the intrinsic interaction between lipid and glucose metabolism, it was not surprising to find that FXR was also involved in the regulation of glucose levels. FXR regulates gene expression of phosphoenolpyruvate carboxykinase (PEPCK) [55], which is a key enzyme of the hepatic gluconeogenesis pathway, by catalyzing a critical step in gluconeogenesis. However, recent observations of glucose levels in $\mathrm{FXR}^{-/-}$mice have produced conflicting results. Glucose levels are shown to be unchanged [56], increased [57] or repressed [58] in FXR null mice compared to the wild-type littermates. This may be due to the different genetic backgrounds of experimental animals used or different experimental approaches. In contrast, two reports have provided consistent results that activation of FXR in wild-type or diabetic $[\mathrm{db} / \mathrm{db}$ or KKA-(y)] mice promotes hypoglycemia and increases insulin sensitivity $[56,57]$.

\section{New functions of FXR}

Recently, several new functions of FXR beyond its roles in metabolism were discovered. For example, activation of FXR induces the expression of several genes involved in enteroprotection, which may explain the previous observation that BAs can inhibit bacterial growth in the intestine $[59,60]$. Because higher levels of BAs have been linked to human colon cancer, it will be interesting to know if FXR plays a role in colon carcinogenesis. In addition, our group and others have identified novel functions of FXR in liver regeneration and hepatocarcinogenesis.

\section{FXR and liver regeneration}

Liver regeneration after the loss of hepatic tissue is an important function of liver to repair injury. It is an adaptive response induced by specific external stimuli, and executed through subsequent sequential changes in gene expression, growth factor production, and morphologic reconstruction. Liver regeneration consists of several well-orchestrated phases, with rapid induction of proliferative factors that activate the quiescent hepatocytes and prime their subsequent progression through the cell cycle, followed by re-establishment of normal liver size and renewed hepatocyte quiescence [6, 61]. Although many genes and signaling pathways are involved in liver regeneration, the essential circuitry required for this process is defined mainly by three major networks: cytokines, growth factors, and metabolic signaling [62]. Secretion of several growth factors and cytokines such as HGF, TGF- $\alpha$, TNF- $\alpha$, and IL-6 is an important early 
response in liver regeneration. Activation of these potent signaling pathways increases expression of many downstream target genes via activation or induction of several transcription factors, including Stat3, NF- $\kappa \mathrm{B}, \mathrm{AP}-1$, and $\mathrm{c}-\mathrm{Myc}$ [61]. Compared to the cytokine and growth factor networks, little is known about the roles of metabolic signals in liver regeneration. It has been suggested that the increased metabolic demands on the residual hepatocytes after partial hepatectomy $(\mathrm{PH})$ may be critical signals to activate the machinery specific for hepatocyte replication. Also, metabolic signals may function as a sensor that calibrates the regenerative response according to the body demands [62]. Therefore, identification of the key metabolic signaling pathways in liver regeneration will help us better understand the mechanism of this process and provide novel approaches to manipulate liver regeneration.

Normal liver regeneration is important for restoring the liver mass following liver injury. However, irregular regeneration of hepatocytes, which develops as a result of repeated cycles of necrosis and regeneration in chronic hepatitis, has been reported as an important factor in hepatocarcinogenesis [63]. We will further discuss this issue later.

Previous reports indicate that $70 \%$ hepatectomy increases BA flux and changes expression of several NRs and enzymes involved in BA metabolism [64-66]. We recently showed that normal liver regeneration is dependent on and regulated by FXR [13]. Liver regeneration was accelerated in mice in which BA pools were increased by feeding with a $0.2 \%$ cholic acid (CA) diet. In contrast, decreasing BA pool by feeding with a diet supplemented with the BA sequestering resin, cholestyramine, strongly decreased the rate of liver regeneration. The effects of both CA and cholestyramine feeding on liver regeneration were absent in $\mathrm{FXR}^{-/}$mice, suggesting that FXR is the mediator of the effect of BA signaling on liver regeneration. Furthermore, the rate of liver growth was much slower in the early stages of liver regeneration in $\mathrm{FXR}^{-/-}$mice. Activation of FXR by BAs increased the expression of a Forkhead Box transcription factor, FoxM1b, which was shown to regulate cell cycle progression during liver regeneration [67]. The results thus suggest that FXR is required for liver regeneration after damage possibly by regulating FoxM1b expression. However, whether FoxM1b is a direct target of FXR or indirectly regulated by FXR is still unknown. It is well known that FXR can activate FGF signaling in intestine, which consequently suppresses BA synthesis in liver [45, 46]. However, the potential role of this FGF signaling axis in liver regeneration is still unclear. In addition, the relationship between the FXR-dependent BA signaling and cytokine or growth factor signaling pathways is also unclear. Nonetheless, the identification of a metabolic signaling pathway for liver regeneration suggests that releasing metabolic burden after liver injury could be a critical and integrated part of liver regeneration. It will be interesting in the future to further understand the impact of metabolic signals in liver regeneration. In addition, given the rapidly increasing demand of liver transplantation, targeting FXR pharmacologically may provide a novel approach to accelerate liver regeneration after liver transplantation or surgery.

We now have a more complete picture of FXR function in hepatoprotection. On the one hand, FXR controls the balance of liver metabolism, thereby preventing the deleterious effect of accumulation of toxic metabolic products in liver. On the other hand, once the liver has been subjected to injury, FXR will further participate in liver repair by promoting regeneration and helping restore organ homeostasis. This extraordinary power of hepatoprotection by FXR is essential for the maintenance of normal liver physiology and prevention of liver pathogenesis. Indeed, in the absence of FXR, $\mathrm{FXR}^{-/-}$mice spontaneously developed liver tumors when they aged [14].

\section{FXR and hepatocarcinogenesis}

Liver cancer is one of the most common forms of cancer worldwide. In the United States, the incidence of liver cancer has doubled during the last two decades and liver cancer has become the most rapidly increasing form of cancer. Hepatocellular carcinoma (HCC) is the primary liver tumor that accounts for more than $80 \%$ of all liver tumors. Among the major etiological causes of HCC, hepatitis B and hepatitis C infection, chemicals, alcoholic and nonalcoholic fatty liver diseases, and some metabolic genetic diseases including hemochromatosis and alpha-1-antitrypsin deficiency, have been implicated in liver cancer development, but the exact mechanism of hepatocarcinogenesis remains unknown [68, 69]. HCC is characteristically associated with the pathologically chronic liver diseases of hepatitis and cirrhosis, in which, triggered by chronic liver injury, hepatocytes proliferate continuously and at higher rates than normal liver cells. This uncontrolled proliferation or irregular liver regeneration is in contrast to normal liver regeneration, in which the liver resumes its normal size and stops cell proliferation within a short period of time. Therefore, irregular liver regeneration may constitute a common mechanism of hepatocarcinogenesis regardless of cancer etiology [35, $63]$.

The development of cancer is a multi-step process. Recently, NF- $\kappa \mathrm{B}$ and the inflammatory pathways have 
been shown to be involved in liver tumorigenesis [70]. In a chemical-induced hepatocarcinogenesis model, the role of NF- $\mathrm{BB}$ in hepatocyte protection is shown to be critical to prevent liver injury and the consequent irregular liver regeneration [71-73]. In the absence of NF$\kappa \mathrm{B}$, the induced hepatocyte proliferation during irregular liver regeneration provides an HCC-promoting environment that favors the selection of transformed cells and promotes tumor formation. Similarly, several metabolic diseases have also been shown to result in chronic liver injury and irregular liver regeneration, thereby promoting hepatocarcinogenesis $[68,69,74,75]$. These common pathological changes were also observed during hepatocarcinogenesis in $\mathrm{FXR}^{-/}$mice.

$\mathrm{FXR}^{-/-}$mice spontaneously developed liver tumors including hepatocellular adenoma and carcinoma between 13-15 months of age [14]. Both serum and liver BA levels were significantly higher in $\mathrm{FXR}^{-/-}$mice compared to the wild-type controls. BAs have been implicated in the induction of liver apoptosis and injury [76]. BAs can promote liver tumors in a HBV transgenic mouse model and are thought to induce inflammation and liver tumorigenesis in mdr-2 knockout mice [77-79]. This is now further confirmed in our study as feeding of a cholic-aciddiet promoted chemical-induced hepatocarcinogenesis [14].

In parallel, Kim et al. [15] reported very similar findings that, at 12 months of age, both male and female $\mathrm{FXR}^{-/-}$mice had a high incidence of degenerative hepatic lesions, altered cell foci, and liver tumors including hepatocellular adenoma, carcinoma, and hepatocholangiocellular carcinoma. The major findings between these two studies are very similar, especially the pathological changes of liver in $\mathrm{FXR}^{-/}$mice including liver injury, irregular regeneration, and strong inflammation. These results suggest that FXR may provide an intriguing link between metabolic regulation and hepatocarcinogenesis. However, the mechanism by which FXR suppresses liver cancer remains to be investigated. The fact that FXR is required for both liver regeneration and protection against hepatocarcinogenesis suggests an intrinsic link between liver regeneration and hepatocarcinogenesis. We hypothesize that FXR has dual roles in helping the liver maintain normal homeostasis: one is by controlling the BA level in liver, the other is by promoting liver repair through regeneration (Figure 2). However, the FXR-dependent liver regeneration is to prevent further liver injury and proliferation. Therefore, FXR is rather working as a tumor suppressor. In the absence of FXR, the cycle of injury and compensatory liver regeneration (irregular liver regeneration) provides a tumor-prone environment. This is consistent with a recent report regarding the role

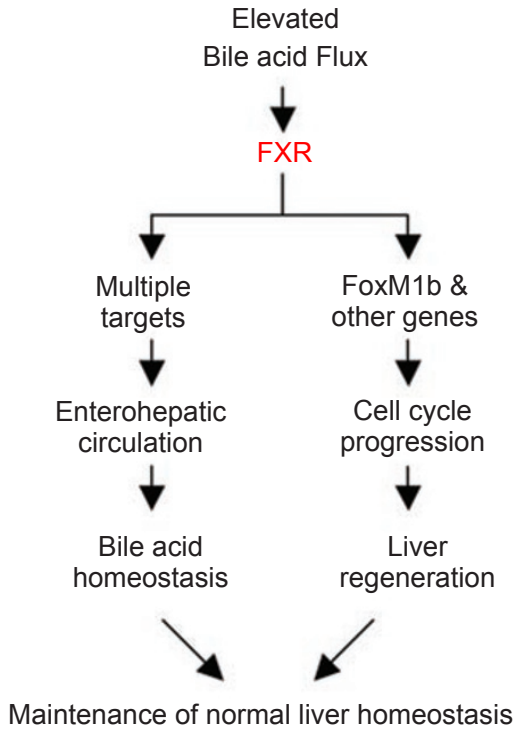

Figure $2 \mathrm{~A}$ model of dual effects of FXR function. In response to the increased bile acid flux, FXR regulates genes involved in both bile acid homeostasis and liver regeneration, which helps maintain normal liver homeostasis.

of NF- $\mathrm{KB}$ in liver injury and hepatocarcinogenesis [70].

The precise roles of FXR in hepatocarcinogenesis need to be further defined. However, a potential contribution of FXR in tumor suppression may be attributed to its anti-fibrosis function in liver [80, 81]. Chronic liver fibrosis has been linked to hepatocarcinogenesis when it finally develops into cirrhosis. Fiorucci et al. $[80,81]$ used a novel FXR ligand, 6-ECDCA, to demonstrate that activation of FXR in stellate cells inhibited pro-fibrosis gene expression in cooperation with two other NRs, Shp and PPAR $\alpha$.

The roles of FXR in carcinogenesis are not necessarily restricted to liver. FXR is expressed in non-enterohepatic tissues, including at high levels in the kidneys and adrenal gland, which are "non-classic" BA targets [4], and low levels in the heart, vascular tissue, thymus, ovary, spleen, testes, and adipose tissue [5, 82]. The functions of FXR in these non-enterohepatic tissues are poorly understood, particularly in humans. It has been reported that FXR is expressed in human breast cancer tissues and cell lines $[61,83]$. Breast cancer is epidemiologically linked to high-fat diets and high levels of BAs in the body [84]. BAs are present at high concentrations in the plasma of postmenopausal women with breast cancer and in breast cysts. Swales et al. [83] showed that FXR activation by CDCA and GW4064 induced breast cancer cell apoptosis. In contrast, Journe et al. [61] showed that the FXR activator, farnesol, induced breast cancer cell growth. 
We also found that FXR ligands CDCA and GW4064 induced proliferation of MCF-7 breast cancer cells (unpublished data). Further studies are needed to understand FXR function in breast cancer cell growth and to decipher the roles of FXR in breast cancer development.

\section{Prospects}

The function of FXR is expanded rapidly from initial roles in controlling metabolism to regulating cell growth and malignancy. The novel roles of FXR in promoting liver regeneration and protecting against hepatocarcinogenesis, however, are consistent with its previously defined functions in regulating BA metabolism and defending against BA toxicity. Therefore, we conclude that FXR is an important cell protector. We expect that further investigation of FXR function in these new areas will provide novel insights into the complex mechanism of liver regeneration and hepatocarcinogenesis.

\section{Acknowledgments}

We apologize to colleagues whose work could not be cited due to space limitations. We thank Dr Barry M Forman (City of Hope) for his suggestion. The authors are grateful to Keely Walker (City of Hope) for proofreading the manuscript. WH is supported by the Sidney Kimmel Foundation for Cancer Research, the Margaret E Early Medical Research Trust, and STOP CANCER Foundation, USA.

\section{References}

1 Chawla A, Repa JJ, Evans RM, Mangelsdorf DJ. Nuclear receptors and lipid physiology: opening the X-files. Science 2001; 294:1866-1870.

2 Forman BM, Goode E, Chen J, et al. Identification of a nuclear receptor that is activated by farnesol metabolites. Cell 1995; 81:687-693.

3 Wang YD, Chen WD, Huang W. FXR, a target for different diseases. Histol Histopathol 2008; 23:621-627.

4 Bishop-Bailey D, Walsh DT, Warner TD. Expression and activation of the farnesoid $\mathrm{X}$ receptor in the vasculature. Proc Natl Acad Sci USA 2004; 101:3668-3673.

5 Zhang Y, Kast-Woelbern HR, Edwards PA. Natural structural variants of the nuclear receptor farnesoid $X$ receptor affect transcriptional activation. J Biol Chem 2003; 278:104-110.

6 Fausto N. Liver regeneration. J Hepatol 2000; 32:19-31.

7 Mangelsdorf DJ, Thummel C, Beato M, et al. The nuclear receptor superfamily: the second decade. Cell 1995; 83:835-839.

8 Glass CK. Differential recognition of target genes by nuclear receptor monomers, dimers, and heterodimers. Endocr Rev 1994; 15:391-407.

9 Cai SY, Xiong L, Wray CG, Ballatori N, Boyer JL. The farnesoid X receptor FXRalpha/NR1H4 acquired ligand specificity for bile salts late in vertebrate evolution. Am J Physiol Regul Integr Comp Physiol 2007; 293:R1400-R1409.

10 Otte K, Kranz H, Kober I, et al. Identification of farnesoid X receptor beta as a novel mammalian nuclear receptor sensing lanosterol. Mol Cell Biol 2003; 23:864-872.

11 Huber RM, Murphy K, Miao B, et al. Generation of multiple farnesoid-X-receptor isoforms through the use of alternative promoters. Gene 2002; 290:35-43

12 Zhang Y, Edwards PA. FXR signaling in metabolic disease. FEBS Lett 2008; 582:10-18.

13 Huang W, Ma K, Zhang J, et al. Nuclear receptor-dependent bile acid signaling is required for normal liver regeneration. Science 2006; 312:233-236.

14 Yang F, Huang X, Yi T, Yen Y, Moore DD, Huang W. Spontaneous development of liver tumors in the absence of the bile acid receptor farnesoid X receptor. Cancer Res 2007; 67:863867.

15 Kim I, Morimura K, Shah Y, Yang Q, Ward JM, Gonzalez FJ. Spontaneous hepatocarcinogenesis in farnesoid $\mathrm{X}$ receptornull mice. Carcinogenesis 2007; 28:940-946.

16 Wang H, Chen J, Hollister K, Sowers LC, Forman BM. Endogenous bile acids are ligands for the nuclear receptor FXR/ BAR. Mol Cell 1999; 3:543-553.

17 Makishima M, Okamoto AY, Repa JJ, et al. Identification of a nuclear receptor for bile acids. Science 1999; 284:1362-1365.

18 Parks DJ, Blanchard SG, Bledsoe RK, et al. Bile acids: natural ligands for an orphan nuclear receptor. Science 1999; 284:1365-1368.

19 Deng R, Yang D, Yang J, Yan B. Oxysterol 22(R)-hydroxycholesterol induces the expression of the bile salt export pump through nuclear receptor farsenoid X receptor but not liver $\mathrm{X}$ receptor. J Pharmacol Exp Ther 2006; 317:317-325.

20 Wang S, Lai K, Moy FJ, Bhat A, Hartman HB, Evans MJ. The nuclear hormone receptor farnesoid X receptor (FXR) is activated by androsterone. Endocrinology 2006; 147:4025-4033.

21 Zhao A, Yu J, Lew JL, Huang L, Wright SD, Cui J. Polyunsaturated fatty acids are FXR ligands and differentially regulate expression of FXR targets. DNA Cell Biol 2004; 23:519-526.

22 Nishimaki-Mogami T, Une M, Fujino T, et al. Identification of intermediates in the bile acid synthetic pathway as ligands for the farnesoid X receptor. J Lipid Res 2004; 45:1538-1545.

23 Dussault I, Beard R, Lin M, et al. Identification of gene-selective modulators of the bile acid receptor FXR. J Biol Chem 2003; 278:7027-7033.

24 Maloney PR, Parks DJ, Haffner CD, et al. Identification of a chemical tool for the orphan nuclear receptor FXR. $J$ Med Chem 2000; 43:2971-2974.

25 Costantino G, Macchiarulo A, Entrena-Guadix A, Camaioni E, Pellicciari R. Binding mode of 6ECDCA, a potent bile acid agonist of the farnesoid X receptor (FXR). Bioorg Med Chem Lett 2003; 13:1865-1868.

26 Mi LZ, Devarakonda S, Harp JM, et al. Structural basis for bile acid binding and activation of the nuclear receptor FXR. Mol Cell 2003; 11:1093-1100.

27 Pellicciari R, Fiorucci S, Camaioni E, et al. 6alpha-ethyl-chenodeoxycholic acid (6-ECDCA), a potent and selective FXR agonist endowed with anticholestatic activity. $\mathrm{J}$ Med Chem 2002; 45:3569-3572.

28 Modica S, Moschetta A. Nuclear bile acid receptor FXR as 
pharmacological target: are we there yet? FEBS Lett 2006; 580:5492-5499.

29 Claudel T, Staels B, Kuipers F. The Farnesoid X receptor: a molecular link between bile acid and lipid and glucose metabolism. Arterioscler Thromb Vasc Biol 2005; 25:2020-2030.

30 Cariou B, Staels B. FXR: a promising target for the metabolic syndrome? Trends Pharmacol Sci 2007; 28:236-243.

31 Lee FY, Lee H, Hubbert ML, Edwards PA, Zhang Y. FXR, a multipurpose nuclear receptor. Trends Biochem Sci 2006; 31:572-580.

32 Song CS, Echchgadda I, Baek BS, et al. Dehydroepiandrosterone sulfotransferase gene induction by bile acid activated farnesoid X receptor. J Biol Chem 2001; 276:42549-42556.

33 Li J, Pircher PC, Schulman IG, Westin SK. Regulation of complement $\mathrm{C} 3$ expression by the bile acid receptor FXR. $J$ Biol Chem 2005; 280:7427-7434.

34 Ananthanarayanan M, Balasubramanian N, Makishima M, Mangelsdorf DJ, Suchy FJ. Human bile salt export pump promoter is transactivated by the farnesoid $\mathrm{X}$ receptor/bile acid receptor. J Biol Chem 2001; 276:28857-28865.

35 Shibata M, Morizane T, Uchida T, et al. Irregular regeneration of hepatocytes and risk of hepatocellular carcinoma in chronic hepatitis and cirrhosis with hepatitis-C-virus infection. Lancet 1998; 351:1773-1777.

36 Grober J, Zaghini I, Fujii H, et al. Identification of a bile acidresponsive element in the human ileal bile acid-binding protein gene. Involvement of the farnesoid X receptor/9-cis-retinoic acid receptor heterodimer. J Biol Chem 1999; 274:2974929754.

37 Goodwin B, Jones SA, Price RR, et al. A regulatory cascade of the nuclear receptors FXR, SHP-1, and LRH-1 represses bile acid biosynthesis. Mol Cell 2000; 6:517-526.

38 Pircher PC, Kitto JL, Petrowski ML, et al. Farnesoid X receptor regulates bile acid-amino acid conjugation. J Biol Chem 2003; 278:27703-27711.

39 Urizar NL, Dowhan DH, Moore DD. The farnesoid X-activated receptor mediates bile acid activation of phospholipid transfer protein gene expression. J Biol Chem 2000; 275:3931339317.

40 Laffitte BA, Kast HR, Nguyen CM, Zavacki AM, Moore DD, Edwards PA. Identification of the DNA binding specificity and potential target genes for the farnesoid X-activated receptor. $J$ Biol Chem 2000; 275:10638-10647.

41 Anisfeld AM, Kast-Woelbern HR, Meyer ME, et al. Syndecan-1 expression is regulated in an isoform-specific manner by the farnesoid-X receptor. J Biol Chem 2003; 278:2042020428.

42 Kast HR, Goodwin B, Tarr PT, et al. Regulation of multidrug resistance-associated protein 2 (ABCC2) by the nuclear receptors pregnane $\mathrm{X}$ receptor, farnesoid $\mathrm{X}$-activated receptor, and constitutive androstane receptor. J Biol Chem 2002; 277:29082915.

43 Claudel T, Sturm E, Duez H, et al. Bile acid-activated nuclear receptor FXR suppresses apolipoprotein A-I transcription via a negative FXR response element. J Clin Invest 2002; 109:961971.

44 Lu TT, Makishima M, Repa JJ, et al. Molecular basis for feedback regulation of bile acid synthesis by nuclear receptors. Mol Cell 2000; 6:507-515.
45 Inagaki T, Choi M, Moschetta A, et al. Fibroblast growth factor 15 functions as an enterohepatic signal to regulate bile acid homeostasis. Cell Metab 2005; 2:217-225.

46 Holt JA, Luo G, Billin AN, et al. Definition of a novel growth factor-dependent signal cascade for the suppression of bile acid biosynthesis. Genes Dev 2003; 17:1581-1591.

47 Hubbert ML, Zhang Y, Lee FY, Edwards PA. Regulation of hepatic Insig-2 by the farnesoid X receptor. Mol Endocrinol 2007; 21:1359-1369.

48 Sinal CJ, Tohkin M, Miyata M, Ward JM, Lambert G, Gonzalez FJ. Targeted disruption of the nuclear receptor FXR/BAR impairs bile acid and lipid homeostasis. Cell 2000; 102:731744.

49 Kok T, Hulzebos CV, Wolters H, et al. Enterohepatic circulation of bile salts in farnesoid $\mathrm{X}$ receptor-deficient mice: efficient intestinal bile salt absorption in the absence of ileal bile acid-binding protein. J Biol Chem 2003; 278:41930-41937.

50 Edwards PA, Kast HR, Anisfeld AM. BAREing it all: the adoption of LXR and FXR and their roles in lipid homeostasis. $J$ Lipid Res 2002; 43:2-12.

51 Anisfeld AM, Kast-Woelbern HR, Lee H, Zhang Y, Lee FY, Edwards PA. Activation of the nuclear receptor FXR induces fibrinogen expression: a new role for bile acid signaling. $J$ Lipid Res 2005; 46:458-468.

52 Sirvent A, Claudel T, Martin G, et al. The farnesoid X receptor induces very low density lipoprotein receptor gene expression. FEBS Lett 2004; 566:173-177.

53 Zhang Y, Castellani LW, Sinal CJ, Gonzalez FJ, Edwards PA. Peroxisome proliferator-activated receptor-gamma coactivator 1alpha (PGC-1alpha) regulates triglyceride metabolism by activation of the nuclear receptor FXR. Genes Dev 2004; 18:157169.

54 Watanabe M, Houten SM, Wang L, et al. Bile acids lower triglyceride levels via a pathway involving FXR, SHP, and SREBP-1c. J Clin Invest 2004; 113:1408-1418.

55 Stayrook KR, Bramlett KS, Savkur RS, et al. Regulation of carbohydrate metabolism by the farnesoid X receptor. Endocrinology 2005; 146:984-991.

56 Zhang Y, Lee FY, Barrera G, et al. Activation of the nuclear receptor FXR improves hyperglycemia and hyperlipidemia in diabetic mice. Proc Natl Acad Sci USA 2006; 103:1006-1011.

57 Ma K, Saha PK, Chan L, Moore DD. Farnesoid X receptor is essential for normal glucose homeostasis. J Clin Invest 2006; 116:1102-1109.

58 Cariou B, van Harmelen K, Duran-Sandoval D, et al. The farnesoid $\mathrm{X}$ receptor modulates adiposity and peripheral insulin sensitivity in mice. J Biol Chem 2006; 281:11039-11049.

59 Berg RD. Bacterial translocation from the gastrointestinal tract. Trends Microbiol 1995; 3:149-154.

60 Ding JW, Andersson R, Soltesz V, Willen R, Bengmark S. The role of bile and bile acids in bacterial translocation in obstructive jaundice in rats. Eur Surg Res 1993; 25:11-19.

61 Journe F, Laurent G, Chaboteaux C, et al. Farnesol, a mevalonate pathway intermediate, stimulates $\mathrm{MCF}-7$ breast cancer cell growth through farnesoid-X-receptor-mediated estrogen receptor activation. Breast Cancer Res Treat 2008; 107:49-61.

62 Fausto N, Campbell JS, Riehle KJ. Liver regeneration. Hepatology 2006; 43:S45-S53.

63 Ueno Y, Moriyama M, Uchida T, Arakawa Y. Irregular regen- 
eration of hepatocytes is an important factor in the hepatocarcinogenesis of liver disease. Hepatology 2001; 33:357-362.

64 Leong GF, Pessotti RL, Brauer RW. Liver function in regenerating fat liver. CrPO4 colloid uptake and bile flow. Am J Physiol 1959; 197:880-886.

65 Garcia-Marin JJ, Regueiro P, Perez-Antona JC, Villanueva GR, Perez-Barriocanal F. Pre-replicative phase-related changes in bile acid-induced choleresis in the regenerating rat liver. Clin Sci (Lond) 1990; 78:55-62.

66 Monte MJ, El-Mir MY, Sainz GR, Bravo P, Marin JJ. Bile acid secretion during synchronized rat liver regeneration. Biochim Biophys Acta 1997; 1362:56-66.

67 Wang X, Krupczak-Hollis K, Tan Y, Dennewitz MB, Adami GR, Costa RH. Increased hepatic Forkhead Box M1B (FoxM1B) levels in old-aged mice stimulated liver regeneration through diminished p27Kip1 protein levels and increased Cdc25B expression. J Biol Chem 2002; 277:44310-44316.

68 Deugnier Y, Turlin B. Iron and hepatocellular carcinoma. $J$ Gastroenterol Hepatol 2001; 16:491-494.

69 Propst T, Propst A, Dietze O, Judmaier G, Braunsteiner H, Vogel W. Prevalence of hepatocellular carcinoma in alpha-1antitrypsin deficiency. J Hepatol 1994; 21:1006-1011.

70 Karin M. Nuclear factor-kappaB in cancer development and progression. Nature 2006; 441:431-436.

71 Luedde T, Beraza N, Kotsikoris V, et al. Deletion of NEMO/ IKKgamma in liver parenchymal cells causes steatohepatitis and hepatocellular carcinoma. Cancer Cell 2007; 11:119-132.

72 Maeda S, Kamata H, Luo JL, Leffert H, Karin M. IKKbeta couples hepatocyte death to cytokine-driven compensatory proliferation that promotes chemical hepatocarcinogenesis. Cell 2005; 121:977-990.

73 Sakurai T, Maeda S, Chang L, Karin M. Loss of hepatic NFkappa B activity enhances chemical hepatocarcinogenesis through sustained c-Jun N-terminal kinase 1 activation. Proc Natl Acad Sci USA 2006; 103:10544-10551.

74 Bianchi L. Glycogen storage disease I and hepatocellular tumours. Eur J Pediatr 1993; 152:S63-S70.
75 Wilkinson ML, Portmann B, Williams R. Wilson's disease and hepatocellular carcinoma: possible protective role of copper. Gut 1983; 24:767-771.

76 Higuchi H, Gores GJ. Bile acid regulation of hepatic physiology: IV. Bile acids and death receptors. Am J Physiol Gastrointest Liver Physiol 2003; 284:G734-G738.

77 Barone M, Maiorano E, Ladisa R, et al. Influence of ursodeoxycholate-enriched diet on liver tumor growth in HBV transgenic mice. Hepatology 2003; 37:880-886.

78 Katzenellenbogen M, Pappo O, Barash H, et al. Multiple adaptive mechanisms to chronic liver disease revealed at early stages of liver carcinogenesis in the Mdr2-knockout mice. Cancer Res 2006; 66:4001-4010.

79 Mauad TH, van Nieuwkerk CM, Dingemans KP, et al. Mice with homozygous disruption of the mdr2 P-glycoprotein gene. A novel animal model for studies of nonsuppurative inflammatory cholangitis and hepatocarcinogenesis. Am J Pathol 1994; 145:1237-1245.

80 Fiorucci S, Antonelli E, Rizzo G, et al. The nuclear receptor SHP mediates inhibition of hepatic stellate cells by FXR and protects against liver fibrosis. Gastroenterology 2004; 127:1497-1512.

81 Fiorucci S, Rizzo G, Antonelli E, et al. Cross-talk between farnesoid-X-receptor (FXR) and peroxisome proliferator-activated receptor gamma contributes to the antifibrotic activity of FXR ligands in rodent models of liver cirrhosis. J Pharmacol Exp Ther 2005; 315:58-68.

82 Zhang Y, Wang X, Vales C, et al. FXR deficiency causes reduced atherosclerosis in Ldlr-/- mice. Arterioscler Thromb Vasc Biol 2006; 26:2316-2321.

83 Swales KE, Korbonits M, Carpenter R, Walsh DT, Warner TD, Bishop-Bailey D. The farnesoid $\mathrm{X}$ receptor is expressed in breast cancer and regulates apoptosis and aromatase expression. Cancer Res 2006; 66:10120-10126.

84 Costarelli V, Sanders TA. Plasma deoxycholic acid concentration is elevated in postmenopausal women with newly diagnosed breast cancer. Eur J Clin Nutr 2002; 56:925-927. 